\title{
EFEITOS DAS VARIAÇÕES CAMBIAIS SOBRE OS COMPONENTES COMERCIAIS DA CONTA CORRENTE NO BRASIL: 1995-2005*
}

\author{
Jesse Andros Pires de Castilho \\ Joanílio Rodolpho Teixeira \\ Marco Aurélio Ferreira Peres ${ }^{\dagger}$
}

\begin{abstract}
RESUMO
Neste artigo é feita uma análise da influência das variações cambiais sobre os componentes comerciais da conta corrente do balanço de pagamentos no Brasil, no período compreendido entre janeiro de 1995 e janeiro de 2006, com freqüência de dados mensal. O tratamento econométrico adotado fundamentou-se na análise de cointegração. Buscou-se também retirar das elasticidades calculadas os efeitos das mudanças institucionais pela aplicação do índice de Divísia. Pôde-se concluir com razoabilidade aceitável que, sem levar em consideração as mudanças institucionais, as variações cambiais exerceram influência significativa nos componentes da balança comercial do Brasil, no período analisado. Os mecanismos de correção de erros sinalizaram que os desequilíbrios de curto prazo podem ser corrigidos num tempo relativamente curto.
\end{abstract}

Palavras-chave: taxa de câmbio, importações, exportações, mudanças institucionais, elasticidades, Brasil.

\begin{abstract}
In this paper it is analyzed the influence of the exchange rate movements on Brazil's current account from January 1995 to January 2006. The frequency of the data is monthly. The econometric treatment adopted was based on the cointegration analysis. By the application of the Divísia index the effects of the institutional changes on the calculated elasticities were removed. It can be concluded with acceptable certainty that without taking into consideration the institutional changes, the exchange rate variations exerted significant influence on the current account balance in the studied period. The mechanism of correction of error indicated that the unbalances of short term do need a relatively short time to be corrected.
\end{abstract}

Keywords: exchange rate, imports, exports, institutional changes, elasticities, Brazil.

JEL classification: F32, C32, H61, C43.

\footnotetext{
* Os autores agradecem a Charles Lima de Almeida pelos comentários e sugestões sobre o desenvolvimento econométrico.

$\S \quad$ Universidade de Brasília. Endereço para contato: SOS 309, bloco J, ap. 404 - Asa Sul - CEP: 70.362-100 - Brasília - DF. E-mail: jessepc@terra.com.br.

a Professor do Departamento de Economia da Universidade de Brasília. O autor agradece ao CNPq e à CAPES pelo apoio a esta pesquisa. E-mail: joanilioteixeira@hotmail.com.

$\dagger$ Professor do Departamento de Economia da União Pioneira de Integração Social - UPIS - E-mail: marco01681@upis.br.

Recebido em junho de 2007. Aceito para publicação em março de 2008.
} 


\section{INTRODUÇÃo}

No Brasil, após muitas décadas com controles cambiais e alguns poucos anos com um regime de bandas, vive-se desde janeiro de 1999 sob um regime de flutuação cambial relativamente livre. Nesse período, surgiram diversas teorias sobre a formação da taxa de câmbio, cuja característica mais proeminente era a ênfase no papel dos estoques (de riqueza ou dívidas), em detrimento da sabedoria estabelecida, que enfatizava os fluxos (do balanço de pagamentos) e a vigência da chamada "paridade de poder de compra".

Em princípio, a influência da taxa de câmbio no resultado da conta corrente do Balanço de Pagamentos parece ser assunto pouco polêmico no meio econômico e entre policy-makers. A lógica do processo parece ser bastante clara: quando a taxa de câmbio é desvalorizada, são necessários mais reais para adquirir os dólares com os quais se compram os produtos estrangeiros. Dessa forma, os produtos nacionais tornam-se mais baratos no mercado externo, o que aumenta a sua venda; ao mesmo tempo, no mercado interno, os produtos importados ficam mais caros em reais, o que diminui a sua demanda. Portanto, a desvalorização cambial tende a reduzir as importações e incentivar as exportações, enquanto a valorização cambial provoca comportamento oposto.

Apesar de os argumentos teóricos serem convincentes, há que se considerar outros fatores que interferem na magnitude dos efeitos das variações da taxa de câmbio sobre a conta corrente. Primeiro, do grau pass-through ${ }^{2}$ que as empresas importadoras (ou exportadoras) realizam; segundo, da capacidade de desvalorizações nominais alterarem a taxa de câmbio real, e terceiro, da sensibilidade dos fluxos de comércio em relação a desvalorizações reais.

Neste trabalho, verifica-se de forma empírica em que medida os componentes da balança comercial do Brasil responderam a alterações nos preços relativos. Para tanto, analisou-se o período compreendido entre janeiro de 1995 e janeiro de 2006, utilizando-se freqüência de dados mensal.

Com a finalidade de obterem-se cálculos mais depurados, considerando que os componentes da balança comercial relacionam-se diretamente com as variações da taxa de câmbio real, calcula-se, ainda, o índice de Divísia ${ }^{3}$ para esse período, eliminando-se os efeitos discricionários produzidos pelas medidas institucionais sobre a conta corrente, como barreiras protecionistas, incentivos e outras medidas governamentais.

A utilização do índice de Divísia no cálculo das elasticidades-taxa de câmbio real dos componentes da conta corrente do Balanço de Pagamentos é sustentada por uma teoria consistente e possibilita o cálculo da elasticidade corrigida sem as grandes dificuldades de ajuste dos dados.

O modelo econômico desenvolvido para as exportações menos as importações de bens e serviços é uma adaptação inovadora do modelo utilizado por Mesa e Estrada (1996), onde se encontram os fundamentos teóricos que permitem maior desagregação dos componentes da conta corrente. O trabalho de Burstein, Eichenbaum e Rebelo (2004) também dá suporte para essa contribuição.

1 A mesma mercadoria deve custar a mesma coisa em qualquer parte quando medida na mesma moeda de um país.

2 Pass-through é entendido como o repasse das mudanças da taxa de câmbio para os preços comerciáveis.

3 O nome se deve a François Jean Marie Divísia (1889-1964), que desenvolveu o índice com ponderações variáveis na obra L’indice monetaire et la teoria de la monnaie (1926). A técnica da utilização desse índice foi introduzida pela primeira vez por Hulten (1973). 
Quanto ao estudo econométrico, utilizou-se o modelo auto-regressivo de defasagens distribuídas - ADL - e uma análise de cointegração, que fornece uma relação comportamental entre os componentes comerciais da conta corrente e o câmbio real efetivo. Essa análise possibilita uma visão de longo prazo e também a estimação de mecanismos de correção de erros, fornecendo ainda os cálculos das elasticidades de curto prazo das variáveis principais.

Este artigo está dividido em cinco partes assim organizadas: após esta seção introdutória, é apresentada, na Seção 2, uma atualização da literatura sobre os efeitos da taxa de câmbio nas contas externas; na Seção 3, são apresentados os modelos matemáticos e econométricos e a demonstração da determinação do índice de Divísia; na Seção 4, são relatados os resultados econométricos e, finalmente, na última seção são apresentadas as conclusões fundamentadas nos resultados obtidos.

\section{LITERATURA EMPÍRICA}

O debate sobre a evidência empírica dos movimentos da taxa de câmbio ${ }^{4}$ no resultado comercial do balanço de pagamentos tem sido reavivado na recente literatura. ${ }^{5}$ Desde o início do século passado, a teoria do comércio internacional, na versão “abordagem das elasticidades”, conhecida como modelo BRM, fornecia suporte para modelar as relações comerciais entre os países ao longo do tempo. Porém, na década de 1950, com o aumento da importância do comércio internacional, surgiram modelos que passaram a incorporar a determinação da renda na teoria do balanço de pagamentos, com a versão "enfoque da absorção". O grande saldo teórico, segundo Dornbusch (1980), foi a integração da determinação de preços relativos e da renda, prática estipulada pela relação entre economia monetária internacional e macroeconomia. Já nos anos de 1960, a análise padrão era a estática comparativa em modelos com determinação da demanda pela renda e a taxa de câmbio estipulando preços relativos.

Surgem, então, os trabalhos de Mundell (1963), que oferecem estruturas organizadas, incluindo o mercado de ativos e a mobilidade de capital nos modelos de macroeconomia aberta, conhecidos popularmente como modelos macroeconômicos de economia aberta de Mundell-Fleming, que, segundo Gonçalves et al. (1998), são superados por duas novas abordagens, o enfoque monetário do balanço de pagamentos e o enfoque pelo equilíbrio de portfólio, ambos de tradição walrasiana.

Quanto aos resultados empíricos dos saldos comerciais relacionados à variação cambial na economia mundial, podemos citar diversos trabalhos: Edwards (1989) procurou verificar empiricamente se uma desvalorização nominal pode traduzir-se em uma desvalorização real. Ele realizou, então, um estudo com diversos países em diferentes episódios, usando um índice de efetividade como medida. Os seus resultados apontam que, para a maioria dos países em desenvolvimento pesquisados, a desvalorização nominal do câmbio é realmente efetiva para alterar significativamente a taxa de câmbio real, pelo menos no ano inicial. Já a pesquisa de Himarios (1989) mostra que desvalorizações nominais afetam a balança comercial positivamente, mas tal efeito pode levar até três anos para se concretizar.

Para uma revisão mais completa sobre taxa de câmbio, ver De Grauwe e Grimaldi (2002), Reinhart e Rogoff (2002). Para maiores detalhes sobre a literatura ver Marçal et al. (2005). 
Por sua vez, Reinhart (1995), em estudo para 12 países em desenvolvimento, no período de 1970 a 1992, constatou que desvalorizações cambiais obtêm sucesso em corrigir desequilíbrios comerciais e estimular exportações. No entanto, a autora alerta que, devido ao fato de a elasticidade-preço ser baixa, são necessárias grandes desvalorizações para que o efeito gerado na balança comercial seja significativo.

Procurando evidenciar uma relação entre câmbio e importações para a Coréia, Oskooee e Rhee (1997) utilizam um modelo uniequacional e encontram uma baixa elasticidade das importações em relação aos preços relativos $(-0,10)$. Também fazendo uso de um modelo de equação, Carone (1996), em um estudo para os Estados Unidos, no período 1970-1992, monta um modelo auto-regressivo de defasagens distribuídas e chega à conclusão de que somente uma forte desvalorização do dólar poderia dar suporte a um processo de ajustamento do déficit da balança comercial americana; além disso, este fato ocorreria com uma considerável defasagem de tempo. Por sua vez, Burstein, Eichebaum e Rebelo (2004) analisaram o comportamento do câmbio em cinco países em desenvolvimento e concluíram pela robustez das apreciações cambiais nos resultados desses países.

Os estudos neste campo para o Brasil também parecem seguir a mesma linha. Rocha (1997) mostra que, entre 1965 e 1985, os salários explicaram os movimentos da taxa de câmbio e esta contribuiu significativamente para o desempenho das exportações brasileiras. Utilizando uma regressão simples, no período 1963-1988, Amazonas e Barros (1996) concluem que a taxa de câmbio real influi na exportação de manufaturados. Em recente pesquisa para a economia brasileira, Marçal $e t$ al. (2005) analisaram em que medida o saldo comercial responde a alterações de preços relativos. Para o período de análise entre 1980 e 2004, os autores buscaram também avaliar se a relação entre saldo comercial e taxa de câmbio real manteve-se inalterada ao longo do período. A metodologia econométrica utilizada consiste na análise de cointegração multivariada na forma proposta por Johansen nos seus trabalhos clássicos. Os autores concluem pela existência de uma relação estável entre taxa de câmbio real e saldo comercial para a economia brasileira, e argumentam que a explicação para que os estudos da segunda metade dos anos de 1990 tenham colocado em dúvida tal relação deve-se ao grande desequilíbrio que persistiu ao longo de toda essa década. Segundo Marçal et al. (2005), o efeito sobre o saldo comercial demorou cerca de uma década para ser absorvido e, claramente, a desvalorização cambial de 1999 acelerou a correção deste desequilíbrio.

Nos trabalhos citados, apesar de diferenças nos resultados alcançados, parece ser consenso a influência da variação cambial no resultado da balança comercial. Por outro lado, existem alguns trabalhos em que essa relação não é confirmada. Entre eles, podem ser citados, no campo internacional, os estudos de Rose (1990) e Ostry e Rose (1992) e, para o Brasil, os estudos de Carneiro e Mello (1997). No entanto, pode-se considerar que esses trabalhos se inserem na literatura de testes econométricos mais antigos, em contraste com trabalhos mais recentes, que utilizam técnicas mais avançadas e que apresentam, portanto, resultados mais confiáveis. 


\section{RESPOSTAS DAS EXPORTAÇÕES E DAS IMPORTAÇÕES ÀS VARIAÇÕES NOS PREÇOS RELATIVOS: AS ELASTICIDADES}

\subsection{Fundamentação teórica: o modelo}

O modelo econômico utilizado tem como base uma estrutura teórica simples (exportações menos importações de bens e serviços), que permite estudar as variações de cada componente em função das flutuações do câmbio real.

$$
S=X B_{t}(q r)+X S_{t}(q r)-M B_{t}(q r)-M S(q r)
$$

onde: $X S_{t}=$ exportação de serviços; $X B_{t}=$ exportação de bens; $M S_{t}=$ importação de serviços e $M B_{t}=$ importação de bens (todas as variáveis em função de $q r=$ câmbio real).

Derivando em relação ao câmbio, temos:

$$
\frac{d S}{d q r}=\frac{d X B_{t}}{d q r}+\frac{d X S_{t}}{d q r}-\frac{d M B_{t}}{d q r}-\frac{d M S_{t}}{d q r}
$$

Após alguns algebrismos, segue-se:

$\frac{d S}{d q r}=\left(\frac{d X B_{t}}{d q r} \cdot \frac{q r}{X B_{t}}\right) \frac{X B_{t}}{q r}+\left(\frac{d X S_{t}}{d q r} \cdot \frac{q r}{X S_{t}}\right) \frac{X S_{t}}{q r}-\left(\frac{d M B_{t}}{d q r} \cdot \frac{q r}{M B_{t}}\right) \frac{M B_{t}}{q r}-\left(\frac{d M S_{t}}{d q r} \cdot \frac{q r}{M S_{t}}\right) \frac{M S_{t}}{q r}$

onde: $\quad d S=\left(\xi_{X S} \cdot X S+\xi_{X B} \cdot X B-\xi_{M S} \cdot M S-\xi_{M B} \cdot M B\right) \cdot\left(\frac{d q r}{q r}\right)$

sendo $\xi_{i, q r}=$ elasticidade da i-ésima variável em relação ao câmbio.

A equação 4 apresenta a variação na conta corrente decorrente de uma alteração no câmbio. Assim, basta que as elasticidades de cada item sejam estimadas para que seja obtido o impacto de uma desvalorização (valorização) cambial na conta corrente.

Todas as elasticidades da equação foram estimadas via mínimos quadrados ordinários. Para tanto, partiu-se de um modelo auto-regressivo de defasagens distribuídas (ADL), com constante e defasagens tanto para as variáveis dependentes $(M B, M S, X B, X S)$, quanto para a variável independente $(q r)$, todas expressas em logaritmo.

Apesar da existência de críticas procedentes ao se estimar elasticidades via um modelo uniequacional, cabe ressaltar que parte relevante da literatura entre câmbio e conta corrente faz uso de modelos de equação única ou então emprega uma equação de oferta e outra de demanda, mas estimadas separadamente, não constituindo, assim, um sistema de equações simultâneas. 
No presente trabalho, foram estimadas quatro regressões, em que se utilizam as primeiras diferenças dos logaritmos das variáveis dependentes. Assim, temos: logaritmo das importações de serviços; logaritmo das exportações de serviços; logaritmo das exportações de bens e logaritmo das importações de bens. Todas essas regressões são estimadas em relação ao câmbio real efetivo.

\subsection{Os efeitos das mudanças institucionais: metodologia do índice de Divísia}

A idéia de se aplicar o índice de Divísia partiu do pressuposto de se obter duas medidas de sensibilidade da variação da conta corrente em relação ao câmbio real efetivo. A primeira consiste em uma medida da sensibilidade quando considerado o efeito conjunto do crescimento automático dos componentes da conta corrente e das medidas discricionárias em relação ao câmbio real. Ela é obtida pela regressão da série da conta corrente total contra a série da taxa de câmbio real efetivo. A segunda medida expurga o efeito das medidas discricionárias (índice de Divísia), retratando simplesmente a sensibilidade da variação da conta corrente em relação às variações automáticas dos componentes dessa conta.

A característica do índice de Divísia que o elege como o índice ótimo para medir as mudanças tecnológicas é a propriedade da invariância. Essa propriedade faz com que, não havendo mudanças tecnológicas, o índice não apresente variação. Nesse caso, todo crescimento na produção será devido ao aumento dos insumos. Portanto, uma mudança no índice é conseqüência unicamente de variação na produção, associada a todos os tipos de fatores não vinculados a variações nos insumos; ou seja, conseqüência de mudanças tecnológicas.

Analogamente, como conseqüência da propriedade da invariância, que deve ser preservada para o caso da conta corrente, na ausência de mudanças discricionárias, o índice permanecerá constante e toda variação verificada na conta corrente deve ser inteiramente creditada ao comportamento de seus componentes.

A versão discreta para o índice de Divísia Agregativo tem a seguinte forma:

$$
\log D^{*}(n)=\log \left(\frac{S(n)}{S(0)}\right)-\sum_{i=1}^{n} \frac{S(t)-S(t-1)}{S(t)} \cdot \frac{x_{i}(t)}{x_{i}(t-1)}
$$

onde $D$ é o índice de Divísia ${ }^{6}$ para as mudanças discricionárias, $S$, a conta corrente agregada e $x_{i}$ o i-ésimo termo da conta corrente.

A equação 5 possibilita a aplicação empírica do índice de Divísia em sua versão discreta e, por conseguinte, a divisão do crescimento total da conta corrente, observado em determinado período na parcela relacionada às mudanças discricionárias e na parcela imputável ao crescimento automático de seus componentes. Assim, o valor obtido do índice de Divísia para cada componente da conta corrente deve ser subtraído das elasticidades apuradas pelas estimativas econométricas, como desenvolvido na seção seguinte.

6 Para maiores esclarecimentos sobre o cálculo, consultar Choudhry (1979). 


\section{Resultados ECONOMÉtricos}

\subsection{Propriedades das séries}

Como primeira etapa da análise empírica, temos o estudo das propriedades estocásticas das séries temporais, em que se verifica se elas são estacionárias ou não. A Figura 1 traz as séries em nível. As Tabelas 1 e 2 sumarizam os testes de raízes unitárias Dickey e Fuller Aumentado - ADF -, Kwiatkowski-Phillips-Schmidt-Shin - KPSS - e de Phillips-Perron - PP - para o logaritmo das séries em nível e na primeira diferença, respectivamente, i. e., o logaritmo das exportações de serviços, $x s$; o logaritmo das exportações de bens, $x b$; o logaritmo das importações de serviços, $m s$; o logaritmo das importações de bens, $m b$; e o logaritmo do câmbio real, $q r$.

Todos os testes levam em conta uma constante. Para a escolha da defasagem, utilizou-se o critério de Schwarz para a forma geral até 12 defasagens. ${ }^{7}$ Ressalta-se que, apesar de as estatísticasteste na Tabela 1 sugerirem a condição I(0) para a série $m b$, ao nível de significância de $5 \%$ (em específico de $3 \%$ para o teste $\mathrm{ADF}$ ), o teste $\mathrm{ADF}$ com base no critério de Akaike modificado, na Tabela 1.1, mostra ser relevante a escolha da estrutura de defasagem e não corrobora com a condição $\mathrm{I}(0)$, mesmo a $5 \%$ de significância. Dessa forma, não se descarta a hipótese da presença de raiz unitária na série $m b$. A julgar pelas estatísticas alcançadas para as demais variáveis, vê-se que elas são não-estacionárias em nível, ou seja, não são I(0).

7 A fim de ratificar os resultados encontrados, principalmente no que se refere à escolha das defasagens, levou-se a cabo testes de raiz unitária baseados nos procedimento de Ng e Perron (2001), conforme demonstram as Tabelas 1.1 e 2.1. 


\section{Figura 1}

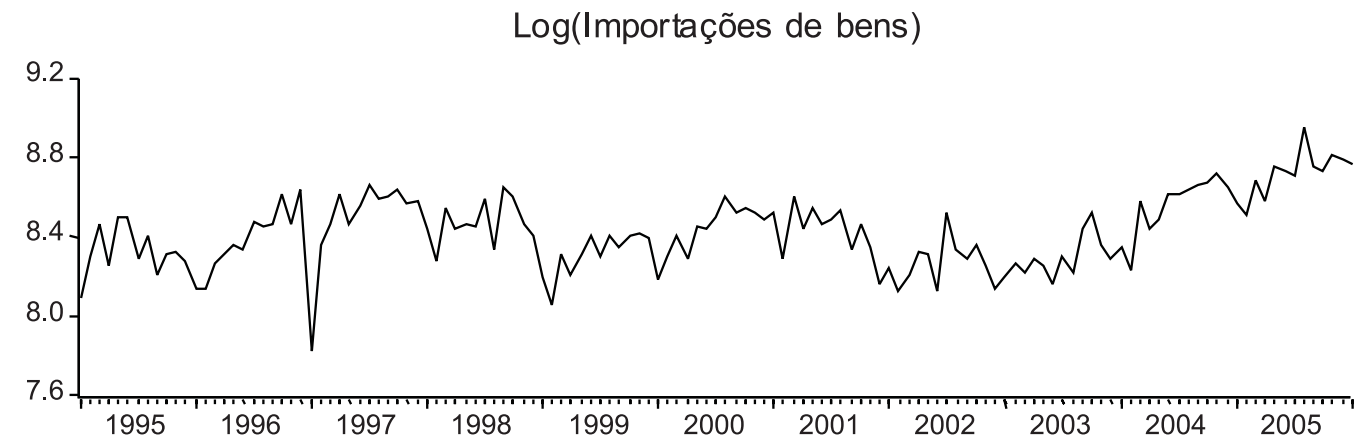

Log(Importações de serviços)

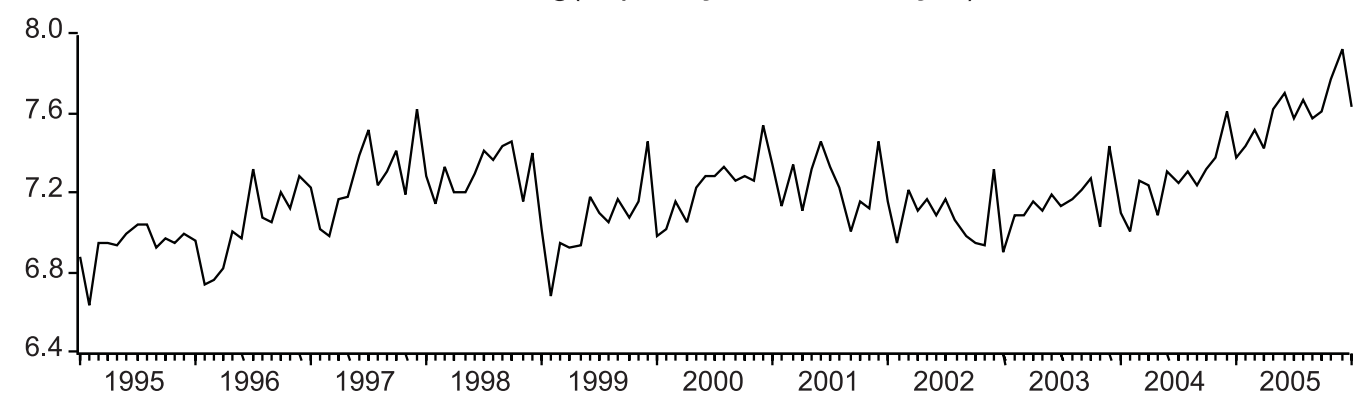

Log(Exportações de bens)

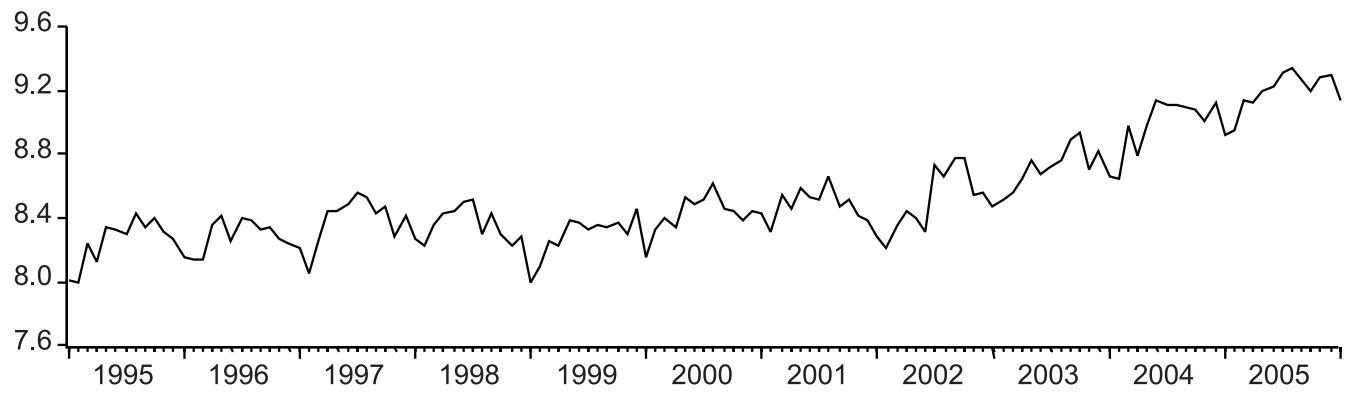

$\log$ (Exportações de serviços)

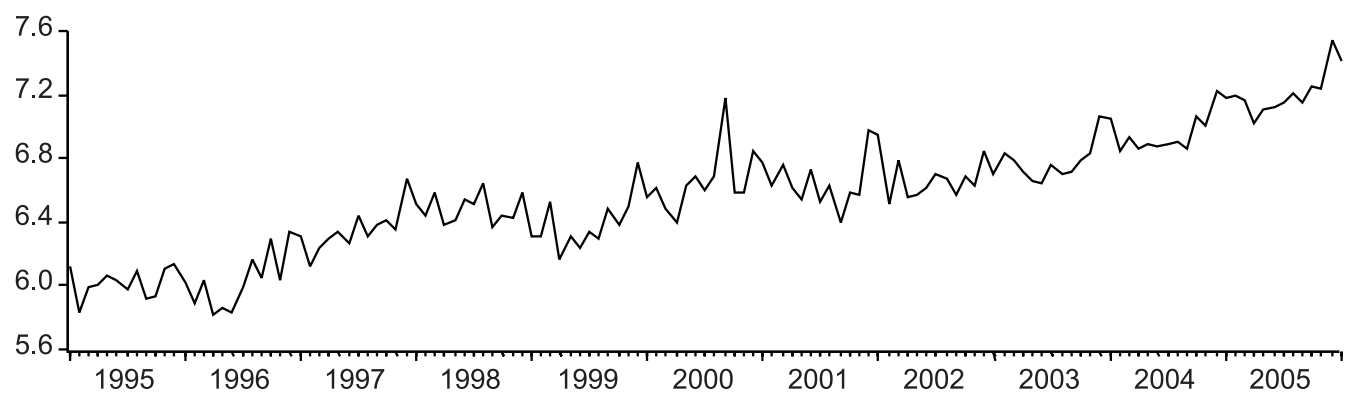




\section{Tabela 1}

\begin{tabular}{lccc}
\hline \multicolumn{5}{c}{ Teste de estacionaridade } \\
\hline \multicolumn{5}{c}{ ADF } & KPSS & PP \\
\hline $1 \%$ & \multicolumn{2}{c}{ Valores críticos } \\
\hline $5 \%$ & $-3,4808$ & 0,7390 & $-3,4804$ \\
\hline Estatística & $-2,8836$ & 0,4630 & $-2,8834$ \\
\hline$x s$ & "t"- (valor-p) & LM & "t"- (valor-p) \\
$x b$ & $-0,5230-(0,880)$ & 1,3118 & $-1,3176-(0,620)$ \\
$m s$ & $-2,0520-(0,999)$ & 1,1612 & $-1,6350-(0,462)$ \\
$m b$ & $-0,8510-(0,800)$ & 0,6165 & $-4,5446-(<0,01)$ \\
$q r$ & $-3,0939-(0,029)$ & 0,3301 & $-5,7541-(<0,01)$ \\
\hline
\end{tabular}

Obs: período de 1995.01 a 2006.01.

\section{Tabela 1.1}

\begin{tabular}{lc}
\hline \multicolumn{2}{c}{ Teste de estacionaridade } \\
\hline Seleção da defasagem: MAIC (max. 12 lag) & ADF \\
\hline Valores críticos & $-3,4808$ \\
\hline $1 \%$ & $-2,8836$ \\
\hline $\mathbf{5} \%$ & "t”- (valor-p) \\
\hline Estatística & $0,1002-(0,964)$ \\
\hline$x s$ & $1,4353-(0,999)$ \\
$x b$ & $-0,8510-(0,800)$ \\
$m s$ & $-0,4495-(0,984)$ \\
$m b$ & $-1,2506-(0,651)$ \\
\hline
\end{tabular}

Obs.: período de 1995.01 a 2006.01.

Para a primeira diferença das séries, todos os testes não consideram o termo constante, exceto para o teste KPSS. Novamente, para a escolha da defasagem, utilizou-se o critério de Schwarz para a forma geral de até 12 defasagens. Conclui-se, para as séries que compõem a Tabela 2, que todas são integradas de primeira ordem, indicadas por I(1), ao nível de significância de $3 \%$ em específico para o teste $\mathrm{ADF}$. 
Tabela 2

\begin{tabular}{lccc}
\hline \multicolumn{4}{c}{ Teste de estacionaridade } \\
\hline Valores críticos & ADF & KPSS & PP \\
\hline $1 \%$ & $-2,5828$ & & $-2,5828$ \\
$\mathbf{5} \%$ & $-1,9433$ & 0,7390 & $-1,9433$ \\
\hline Estatística & "t"- (valor-p) & 0,4630 & "t"- (valor-p) \\
\hline$\Delta x s$ & $-12,82-(<0,01)$ & LM & $-24,14-(<0,01)$ \\
$\Delta x b$ & $-2,14-(0,030)$ & 0,2681 & $-18,24-(<0,01)$ \\
$\Delta m s$ & $-2,36-(0,018)$ & 0,1514 & $-25,09-(<0,01)$ \\
$\Delta m b$ & $-19,34-(0,000)$ & 0,1502 & $26,20-(0,00)$ \\
$\Delta q r$ & $-7,92-(<0,01)$ & 0,1880 & $-7,57-(<0,01)$ \\
\hline
\end{tabular}

Obs.: período de 1995.01 a 2006.01 .

Tabela 2.1

\begin{tabular}{lc}
\hline \multicolumn{2}{c}{ Teste de estacionaridade } \\
\hline Seleção da defasagem: MAIC (max. 12 lag) & ADF \\
\hline Valores críticos & $-3,4808$ \\
\hline $1 \%$ & $-2,8836$ \\
\hline $5 \%$ & "t”- (valor-p) \\
\hline Estatística & $-19,34-(0,00)$ \\
\hline$\Delta x s$ & $-5,97-(0,00)$ \\
$\Delta x b$ & $-18,11-(0,00)$ \\
$\Delta m s$ & $-19,29-(0,00)$ \\
$\Delta m b$ & $-7,59-(0,00)$ \\
\hline$q g r$
\end{tabular}

Obs.: período de 1995.01 a 2006.01 .

De posse dos resultados sobre a estacionaridade das séries, cabe considerar uma importante propriedade das variáveis $\mathrm{I}(0)$ : elas podem ser combinações lineares de variáveis I(1) e, neste caso, são ditas cointegradas. O conceito de cointegração foi introduzido por Granger (1981). Considere duas variáveis, $y_{t}$ e $z_{t}$, e suponha que ambas são I(1). Então, $y_{t}$ e $z_{t}$ são ditas cointegradas se existe $\beta$, tal que $y_{t}-\beta z_{t}$ é I(0). Essa é a versão mais simples do conceito de cointegração, que certamente pode ser generalizado. No entanto, esse conceito é suficiente para esta pesquisa, que tem como metodologia o modelo auto-regressivo de defasagens distribuídas (ADL) das variáveis endógenas $(x s, x b, m s, m b)$ em função do logaritmo do câmbio real, qr. A existência da relação de cointegração indica a presença de um equilíbrio de longo prazo entre as variáveis. Isso significa 
que a equação de regressão do tipo $y_{t}=\beta z_{t}+u_{t}$ faz algum sentido, porque $y_{t}$ e $z_{t}$ não se afastam significativamente ao longo do tempo. Na ausência da cointegração entre $y_{t}$ e $z_{t}$, a relação obtida na equação de regressão anterior deve ser espúria.

Sendo assim, o segundo passo consiste em detectar a existência de cointegração por intermédio de testes usuais, exceto para o logaritmo das importações de bens, $m b$, pois, como visto, $m b$ é $\mathrm{I}(0)$. Utilizou-se, dessa forma, o Teste de Johansen, cujos resultados são apresentados na Tabela 3.

A especificação da forma funcional para o teste acima considera o intervalo de uma defasagem da primeira diferença em todas as equações, exceto para o par $x b$ e $q r$, em que se incluíram três defasagens. A escolha da especificação foi feita a partir dos critérios de informação de Akaike e Schwarz para o posto e para o modelo. Para todas as relações de cointegração, considera-se uma constante e uma tendência linear no mecanismo de correção de erros. Os resultados indicam a existência de uma equação de cointegração para todos pares de séries, no nível de $1 \%$.

Tabela 3 - Teste de cointegração de Johansen

\begin{tabular}{llcccc}
\hline Séries & $N^{0}$ de cointegrações & Autovalor & Traço & Valor crítico a 5\% & Valor crítico a 1\% \\
\hline \multirow{3}{*}{$m s$ e $q r$} & nenhuma* & 0,2002 & 32,1769 & 18,40 & 30,45 \\
& Ao menos 1 & 0,0219 & 2,9085 & 12,25 & 16,26 \\
\multirow{2}{*}{$x$ s e $q r$} & nenhuma** & 0,1734 & 26,7622 & 18,17 & 23,46 \\
& Ao menos 1 & 0,0137 & 1,8073 & 3,74 & 6,40 \\
\multirow{2}{*}{$x b$ e $q r$} & nenhuma* & 0,2690 & 45,4514 & 25,32 & 30,45 \\
& Ao menos 1 & 0,0155 & 2,0175 & 12,25 & 16,26 \\
\hline
\end{tabular}

Obs: o teste do Traço indica a existência de uma equação de cointegração.

Período de 1995/01 a 2006/01.

Notas: $\left.{ }^{* *}\right)$ indica a rejeição da hipótese ao nível de 5\%(1\%). As letras minúsculas indicam o logaritmo.

\subsection{Estratégia para a estimação da elasticidade-câmbio real das variáveis de interesse}

O próximo passo será estimar a elasticidade-câmbio real das variáveis de interesse. A estratégia consiste em partir de um modelo ADL geral para o específico. A teoria sugere que a omissão de variáveis relevantes é mais preocupante que a inclusão de variáveis irrelevantes. Isso porque, no primeiro caso, o estimador possui viés, a variância do erro em geral é sobreestimada e os processos de inferência usuais não são válidos; enquanto que, no segundo caso, o estimador não possui viés, a variância do erro é corretamente estimada e os processos de inferência usuais são válidos.

A idéia é começar com uma estrutura de defasagens tolerante da variável dependente e do câmbio real. ${ }^{8}$ Essa especificação deverá então sujeitar-se aos testes convencionais para autocorrelação, heteroscedasticidade, estabilidade dos parâmetros e erros de especificação. Caso o modelo

8 A abordagem do geral para o particular é devida ao trabalho de Hendry (1976). 
ultrapasse os testes propostos, as etapas seguintes consistirão em investigar se as reduções na estrutura de defasagem são válidas e identificar uma relação de cointegração.

Para todas as variáveis de interesse, partiu-se da especificação geral do modelo ADL que considera um termo constante, uma tendência linear, uma estrutura geral de defasagens composta pelo valor contemporâneo e seis defasagens do logaritmo do câmbio real e a mesma estrutura temporal para a variável dependente. Dessa forma, o modelo geral pode ser escrito como:

$$
y_{j ; t}=\alpha+\beta . t+\sum_{i=0}^{6} \pi_{i} q r_{t-i}+\sum_{i=1}^{6} \gamma_{i} y_{j ; t-i}+u_{t}
$$

onde $y_{j ; t}$ representa as variáveis de interesse: $x s ; x b ; m s ; m b$; e $q r$ : o logaritmo do câmbio real.

Os resultados da estimação sobre toda a amostra da equação ADL geral para todas as variáveis indicam quebra estrutural na mudança do regime cambial, entre o segundo semestre de 1998, quando ocorreu a crise da Rússia, e janeiro de 1999, em que efetivamente ocorreu a mudança. De fato, verifica-se, pela análise do gráfico da série do logaritmo do câmbio real na Figura 2, a presença da quebra estrutural da variável explicativa.

\section{Figura 2}

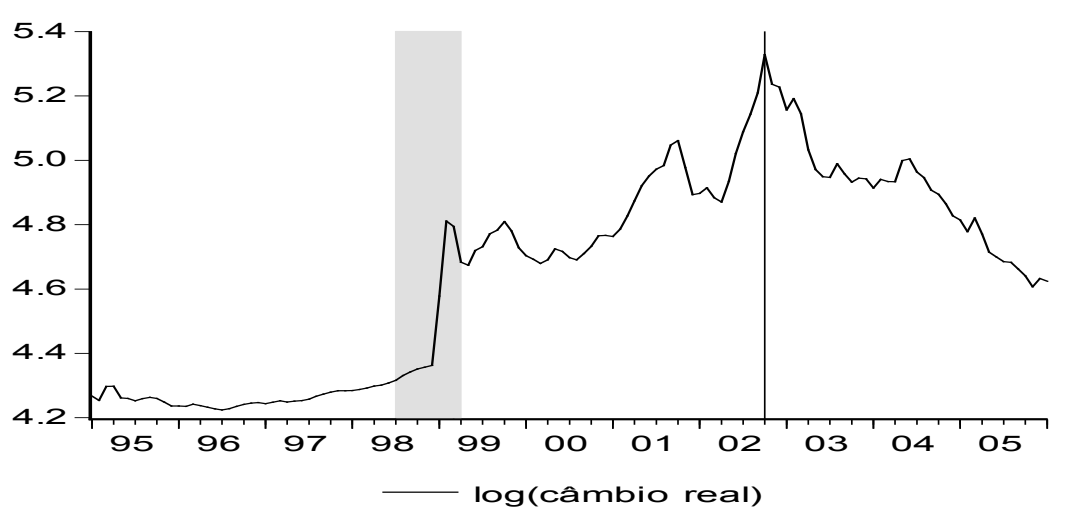

Assim, como possível solução, adota-se a estratégia de investigar a relação entre as variáveis de interesse e o câmbio real em dois períodos distintos: entre janeiro de 1995 e junho de 1998, com regime que pode ser considerado de taxas de câmbio fixas; e, após os ajustes cambiais da mudança de regime, de abril de 1999 a janeiro de 2006, com o câmbio flutuante.

\subsection{Resultados}

Os resultados encontrados para o regime de câmbio fixo (1995:01 a 1998:06) não indicam relação significante entre o câmbio real e as variáveis de interesse. Isso pode estar relacionado com o tamanho da amostra (42 observações), que reduz de forma considerável o grau de liberdade em 
cada estimação. Também há que se considerar que, no período, as variações cambiais foram muito pequenas para explicar o movimento nas exportações e nas importações, o que não constitui uma surpresa, pois, em um arranjo de estabilização econômica com âncora cambial, parece razoável que as contas de comércio exterior respondam mais a outros fatores, tais como os entraves institucionais, do que ao câmbio, que permaneceu relativamente fixo.

Já quanto ao segundo período (1999:04 a 2006:01), os resultados alcançados sobre a propriedade I(1) das séries mantiveram-se inalterados. Assim, de acordo com a metodologia proposta, estimou-se uma equação geral para cada variável de interesse, submetendo cada equação a uma bateria de testes. Dado que todas as séries são I(1), considerou-se a parametrização da equação geral ADL (4.1) como primeiro passo na busca da parcimônia. Essa relação pode ser transformada linearmente, ${ }^{9}$ em termos de polinômios, no operador de defasagem, o que permite escrever:

$$
\Delta y_{t}=\alpha+\beta t+\delta_{0} q r_{t-1}+\sum_{i=0}^{5} \varphi_{i} \Delta q r_{t-i}+\theta_{0} y_{j ; t-1}+\sum_{i=1}^{5} \theta_{i} \Delta y_{t-i}+u_{t}
$$

Ressalta-se que os resíduos na expressão 7 são os mesmos da relação geral 6, e a maior parte das estatísticas-teste de diagnósticos apresenta valores idênticos, quer se estime a relação nos níveis das variáveis ou em primeiras diferenças. Deve-se também destacar que os valores estimados para $\delta_{0}$ em cada equação representam a soma dos coeficientes estimados para o logaritmo do câmbio real em nível na relação. Por sua vez, $\theta_{0}$ é a soma dos coeficientes das defasagens da variável dependente. Como se sabe, essas somas são fundamentais para a existência de uma relação de cointegração. $\mathrm{O}$ interesse está em testar se essas somas são estatisticamente diferentes de zero e, logo, se existe uma relação de longo prazo entre as variáveis de interesse e o câmbio real. Essa é uma das vantagens da parametrização: estimação direta e teste imediato dessas somas. Outra vantagem é que, ao utilizar as primeiras diferenças, é possível reduzir de forma substancial a colinearidade entre os regressores e, conseqüentemente, reduzir os erros padrão.

\subsubsection{Elasticidade-câmbio real das importações}

Considera-se inicialmente a relação para o logaritmo das importações de bens. Como descrito, a equação parametrizada foi submetida a uma bateria de testes. O valor alcançado para a estatística Jarque-Bera não rejeita o pressuposto de normalidade dos resíduos. No teste assintótico de BreushGodfrey para autocorrelação não se rejeita a hipótese de autocorrelação nula dos resíduos. Os testes para resíduos $\mathrm{ARCH}$ não rejeitam a hipótese nula de resíduos homocedásticos em favor de resíduos ARCH. O teste de White para presença de heterocedasticidade rejeita a possibilidade de mudanças na variância dos resíduos.

O teste RESET de Ramsey para erros de especificação não relata má especificação. A estatística LR para o teste de previsão de Chow para os seis últimos meses da amostra possui distribuição qui-quadrado com seis graus de liberdade e não rejeita a hipótese de constância dos parâmetros. Além disto, o teste de Chow para ruptura da série em outubro de 2002 não sugere significativamente a existência de quebra estrutural. Os gráficos do par de testes para a invariabilidade dos parâmetros baseados na quantidade da soma acumulada dos resíduos padronizados e na soma dos

9 Para tornar mais clara a exposição, demonstra-se a transformação polinomial no Apêndice. 
quadrados desses resíduos, CUSUM e CUSUMSQ, respectivamente, confirmam a estabilidade dos parâmetros.

Conforme a estratégia discutida, o próximo passo consiste em procurar reduções seqüenciais da equação geral. Não existe uma seqüência única para encontrar a equação com maior parcimônia. A idéia é identificar as variáveis ou grupos de variáveis redundantes e/ou restrições que possam ser validadas pelos testes $\mathrm{F}$ usuais. De acordo com as estimativas alcançadas, as defasagens de quarta e quinta ordem das duas variáveis envolvidas são não significantes. O teste da significância conjunto para essas variáveis encontra-se nos resultados do primeiro passo da Tabela 4.

\section{Tabela 4}

\begin{tabular}{ccccccc}
\hline Passo & Variável redundante & $\begin{array}{c}\text { S.E da } \\
\text { regressão }\end{array}$ & $\begin{array}{c}\text { Teste } \mathrm{F} \\
(\text { valor-p) }\end{array}$ & $\begin{array}{c}\mathrm{LR} \\
(\text { valor-p) }\end{array}$ & $\begin{array}{c}\mathrm{R}^{2} \\
\text { ajustado }\end{array}$ & SC \\
\hline 0 & & 0.0954 & & & 0.4264 & -1.2572 \\
1 & $\Delta q r_{t-4} ; \Delta q r_{t-5} ; \Delta m b_{t-4} ; \Delta m b_{t-5}$ & 0.0938 & $0.4214(0.7926)$ & $2.0376(0.7288)$ & 0.4451 & -1.4473 \\
2 & \multicolumn{1}{c}{$\Delta q r_{t} ; \Delta q r_{t-3} ; \Delta m b_{t-2}$} & 0.0920 & $0.0679(0.9767)$ & $0.2352(0.9717)$ & 0.4661 & -1.6057 \\
\hline
\end{tabular}

O teste F e o respectivo valor-p não rejeitam a hipótese de que essas defasagens sejam redundantes, sendo, portanto, retiradas da equação. Estimada a regressão sob a nova especificação, notase que tanto o critério de Schwarz como o $\mathrm{R}^{2}$ ajustado movem-se na direção certa. No segundo e último passo na busca por parcimônia, o valor contemporâneo da primeira diferença do logaritmo do câmbio real e sua terceira defasagem, bem como a segunda defasagem da variável dependente são eliminados da equação, de acordo com os testes acima. Novas reduções não são possíveis, já que não melhoram o modelo anterior, assim se opta pelo modelo competitivo abaixo:

$$
\begin{aligned}
& \Delta m b_{t}=6,04+0,0029 t-0,43 q r_{t-1}+0,55 \Delta q r_{t-1}+0,55 \Delta q r_{t-2}-0,50 m b_{t-1}-0,34 \Delta m b_{t-1}+0,25 \Delta m b_{t-3} \\
& \begin{array}{llll}
(t) & (5,22)(4,29) \quad(-4,53) \quad(2,12)
\end{array} \\
& (2,32) \quad(-5,05) \quad(-3,73) \quad(3,12) \\
& R^{2}=0,51 ; F=11,10(\text { valor }-p=0,00)
\end{aligned}
$$

O modelo final para as importações de bens ultrapassou o mesmo conjunto de testes ao qual foi submetida a equação parametrizada geral. O modelo explica cerca de $51 \%$ das mudanças nas importações de bens. Observa-se que as estimativas para as somas dos coeficientes da defasagem do modelo em nível, tanto para o câmbio real quanto para a variável dependente são diferentes de zero. Assim, pode-se reescrever a equação 8 de forma a explicitar a elasticidade de longo prazo, bem como a relação cointegrante. Em termos da estrutura geral parametrizada, ela pode ser escrita como:

$$
\begin{aligned}
& \Delta m b_{t}=\alpha+\beta t+\delta_{0} q r_{t-1}+\varphi_{1} \Delta q r_{t-1}+\varphi_{2} \Delta q r_{t-2}+\theta_{0} m b_{t-1}+\theta_{1} \Delta m b_{t-1}+\theta_{3} \Delta m b_{t-3} \\
& \Delta m b_{t}=+\varphi_{1} \Delta q r_{t-1}+\varphi_{2} \Delta q r_{t-2}+\theta_{1} \Delta m b_{t-1}+\theta_{3} \Delta m b_{t-3}+\theta_{0}\left(m b_{t-1}+\frac{\alpha+\beta t}{\theta_{0}}+\frac{\delta_{0}}{\theta_{0}} q r_{t-1}\right)
\end{aligned}
$$


Substituindo os coeficientes estimados, obtém-se:

$\Delta m b_{t}=+0,55 \Delta q r_{t-1}+0,55 \Delta q r_{t-2}-0,34 \Delta m b_{t-1}+0,25 \Delta m b_{t-3}-0,50\left(m b_{t-1}-12,14-0,006 t+0,87 q r_{t-1}\right)$

onde o termo entre parênteses é a relação cointegrante. ${ }^{10}$ Isso mostra que existem dois efeitos sistemáticos sobre as mudanças nas importações de bens. O primeiro é o efeito multiplicador, $\varphi_{1} \Delta q r_{t-1}$, devido a mudanças no câmbio real no período anterior, que se prolonga por mais um mês com mesma intensidade, por intermédio do termo $\varphi_{2} \Delta q r_{t-2}$. O segundo se deve aos desvios do valor de equilíbrio de longo prazo, dado por $m b_{t-1}=12,14+0,006 t-0,87 q r_{t-1}$. Cerca de $50 \%$ dos desvios do equilíbrio de longo prazo são corrigidos no período corrente. A elasticidade-câmbio real de longo prazo $(-0,87)$ possui sinal correto e deverá ainda ser subtraída do índice de Divísia calculado para o período no valor de 0,15 .

A mesma estrutura de análise pode ser usada para determinar a relação entre o logaritmo das importações de serviços, $m s_{t}$, e o logaritmo do câmbio real, $q r_{t}$. Contudo, será necessário dar um tratamento sazonal para a série do logaritmo das importações de serviços, $m s_{t}$. Uma inspeção na Figura 3 revela que há picos em dezembro de cada ano, em especial entre os anos de 1999-2005, justamente o período em análise.

\section{Figura 3}
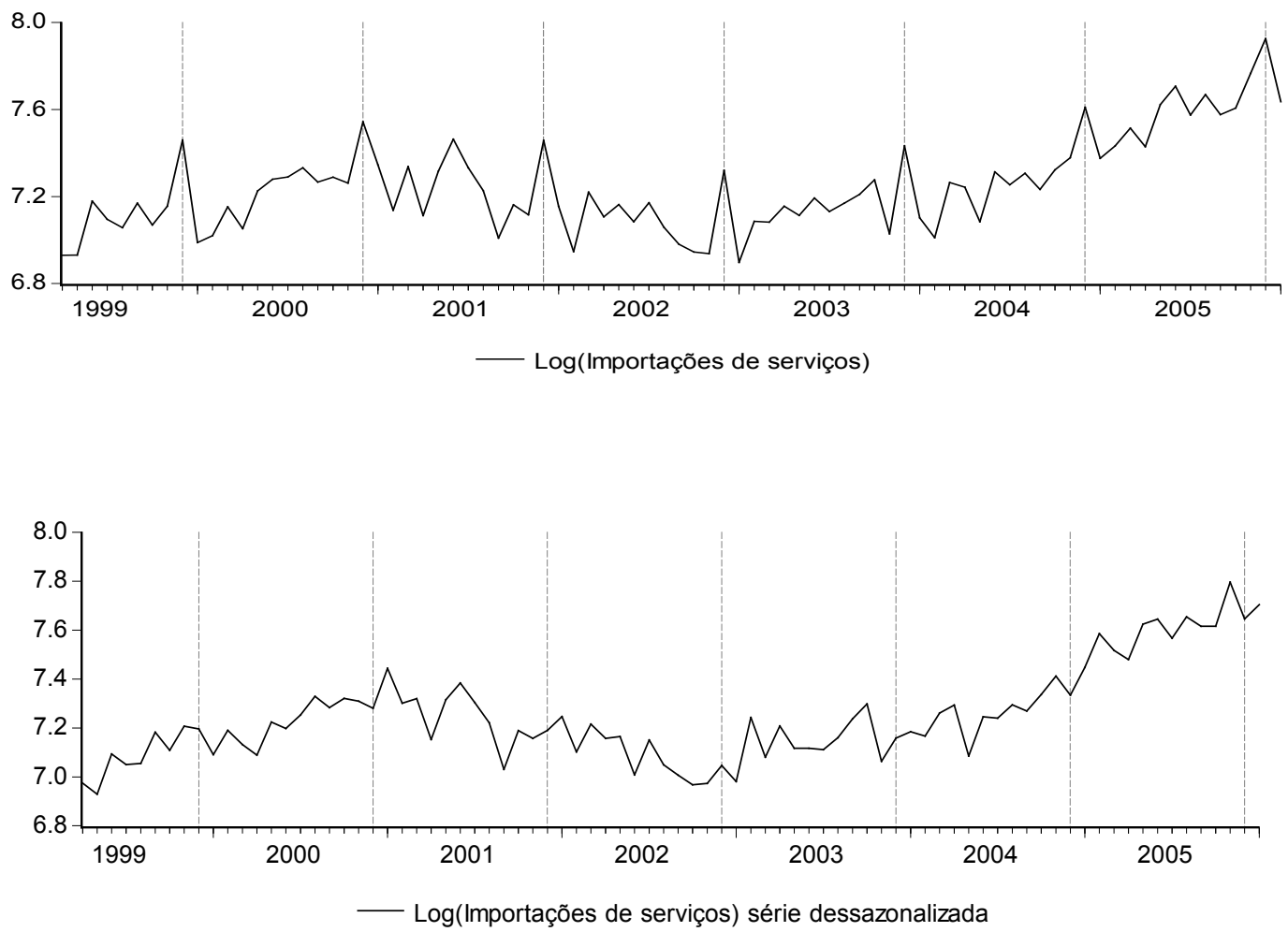

10 Confirmou-se a estacionaridade da relação de cointegração, via teste ADF, para os resíduos da equação do nível logaritmo de $M B_{t-1}$ sobre uma constante, uma tendência e o nível logaritmo de $q r_{t-1}$. 
Portanto, é conveniente levar em conta o comportamento sazonal para evitar o risco de alguma correlação serial nos resíduos. Uma alternativa para tratar o problema seria considerar uma variável de impulso para dezembro de cada ano. Porém, isso poderia implicar multicolinearidade entre o termo de tendência e a variável de impulso. A alternativa adotada foi o ajustamento sazonal via método X-11 aditivo, com dummies sazonais como regressores. Uma inspeção na série do logaritmo das importações de serviços ajustada sazonalmente ${ }^{11}$ revela que permanece a propriedade I(1), o que permite conduzir a investigação empírica conforme descrito antes.

Os resultados encontrados para a especificação geral com as variáveis em nível e em primeiras diferenças, na qual a variável dependente é o logaritmo das importações de serviços com ajuste sazonal, também ultrapassa a bateria de testes. Os testes sobre os resíduos relatam que o pressuposto de normalidade não pode ser rejeitado. Ademais, não há autocorrelação serial e não se rejeita a hipótese de resíduos homocedásticos. O teste para erros de especificação de Ramsey indica que a formulação é correta. A hipótese de instabilidade dos parâmetros é descartada tanto pelos gráficos da soma acumulada dos resíduos, CUSUM e CUSUMSQ, quanto pelo teste de previsão de Chow para os últimos seis meses da amostra. O teste de Chow para quebra estrutural em outubro de 2002 rejeita a hipótese nula a $6 \%$ de significância.

Como antes, a análise do geral para o específico é levada a cabo conforme demonstra a Tabela 5. Nota-se que, das estimativas para ambas as variáveis em primeiras diferenças, as defasagens três a cinco são não significantes e parecem ser um bom começo na busca de um modelo parcimonioso.

\section{Tabela 5}

\begin{tabular}{|c|c|c|c|c|c|c|}
\hline Passo & Variável redundante & $\begin{array}{l}\text { S.E da } \\
\text { regressão }\end{array}$ & $\begin{array}{c}\text { Teste F } \\
\text { (valor-p) }\end{array}$ & $\begin{array}{c}\mathrm{LR} \\
\text { (valor-p) }\end{array}$ & $\mathrm{R}^{2}$ ajustado & SC \\
\hline 0 & & 0.0773 & & & 0.4327 & -1.6459 \\
\hline 1 & $\Delta q r_{t-3} a \Delta q r_{t-5} ; \Delta m s_{t-3} a \Delta m s_{t-5}$ & 0.0764 & $\begin{array}{c}0.9763 \\
(0.4490)\end{array}$ & $6.9684(0.3237)$ & 0.4355 & -1.9270 \\
\hline 2 & $\Delta q r_{t-1}$ & 0.0761 & $\begin{array}{c}0.4483 \\
(0.5053)\end{array}$ & $0.5043(0.4776)$ & 0.4399 & -1.9759 \\
\hline 3 & $\Delta m s_{t-2}$ & 0.0772 & $\begin{array}{c}2.2659 \\
(0.1367)\end{array}$ & $2.4819(0.1151)$ & 0.4332 & -1.9911 \\
\hline
\end{tabular}

O teste de significância para esse conjunto de variáveis recomenda a exclusão, conforme as estatísticas F e LR e seus respectivos valores-p. Feita a redução do modelo, obtêm-se as estatísticas da S.E da regressão, o coeficiente de determinação ajustado e o critério de Shwartz (SC), que validam a redução. O segundo passo revela que a primeira diferença do câmbio defasada de um período também pode ser excluída do modelo. Observa-se que a convergência dos resultados para as estatísticas indicam melhora marginal nesse passo. Por último, no terceiro passo, verifica-se que o testes F e LR não recomendam fortemente a exclusão da variável $\Delta m s_{t-2}$. Ocorre a melhora marginal da estatística SC após a redução do modelo, mas a soma dos erros da regressão e o $\mathrm{R}^{2}$ ajustado não são congruentes com o critério Shwartz. Logo, entende-se que, apesar de a variável ter alcançado

11 Ver Figura 3. 
significância marginal na regressão (valor-p da estatística t em torno de 13\%), ela adiciona informação relevante para explicar as mudanças no logaritmo das importações de serviços. Dessa forma, conclui-se que novas reduções não melhoram o modelo e a equação final pode ser escrita como:

$$
\begin{aligned}
& \Delta m s_{t}=4,65+0,0024 t-0,40 q r_{t-1}-0,74 \Delta q r_{t}+0,58 \Delta q r_{t-2}-0,40 m s_{t-1}-0,43 \Delta m s_{t-1}-0,15 \Delta m s_{t-2} \\
& \begin{array}{llllll}
(s e) & (3,99)(3,49) \quad(-4,08) & (-3,44) & (2,51) & (-3,65) & (-3,71)
\end{array} \\
& R^{2}=0,49 ; F=9,75(\text { valor }-p=0,00)
\end{aligned}
$$

Ainda como estratégia de abordagem, o modelo selecionado foi submetido aos mesmos testes de diagnósticos que o modelo geral. Exceto no que diz respeito à normalidade dos resíduos, todos os testes de diagnósticos referendam a estrutura acima. A normalidade dos resíduos é rejeitada a $5 \%$, mas não a $1 \%$ de significância, o que não destrói as propriedades de eficiência e consistência dos estimadores de mínimos quadrados - procedimentos de inferência possuem validade assintótica. Os resíduos são homocedásticos e não possuem correlação serial. O teste de quebra estrutural em outubro de 2002 e o teste de previsão para os últimos seis meses não indicam quebra estrutural. Todavia, a estimação recursiva dos parâmetros sugere alguma instabilidade entre 1999 e 2002. Os gráficos para a soma acumulada dos resíduos não relatam forte instabilidade nos parâmetros.

Assim, a equação acima pode ser expressa de forma a explicitar a relação de longo prazo, de interesse para a pesquisa:

$$
\Delta m s_{t}=-0,74 \Delta q r_{t}+0,58 \Delta q r_{t-2}-0,43 \Delta m s_{t-1}-0,15 \Delta m s_{t-2}-0,40\left(m s_{t-1}-11,69+0,0059 t+1,01 q r_{t-1}\right),
$$

onde o termo entre parênteses é a relação cointegrante.

Também neste caso, há dois efeitos sistemáticos sobre as mudanças nas importações de serviços: o multiplicador instantâneo, $-0,74 \Delta q r_{t}$, devido a mudanças no câmbio real, e os desvios do valor de equilíbrio de longo prazo, dado por $m s_{t-1}=+11,69-0,0059 t-1,01 q r_{t-1}$.

Nota-se que a relação co-integrante está de acordo com as estatísticas de Johansen na Tabela 3. O coeficiente de ajustamento do mecanismo de correção de erros indica que cerca de $40 \%$ dos desvios do equilíbrio de longo prazo é corrigido no período corrente. A elasticidade-câmbio real de longo prazo $(-1,01)$ possui sinal correto e deve ainda ser subtraída do índice de Divísia, calculado para o período, no valor de 0,07 . Não há uma explicação óbvia para que a segunda defasagem das mudanças no câmbio real seja significativa, podendo ser um efeito real ou uma conseqüência dos procedimentos característicos dos contratos de importação, por exemplo. Todavia, essa defasagem mostrou-se significativa tanto nas importações de bens como nas importações de serviços.

Não se deve desconsiderar a semelhança na estrutura das equações estimadas para as importações de bens e serviços. Além disso, há alguma proximidade nos valores estimados, sobretudo para o mecanismo de correção de erro.

\subsubsection{Elasticidade-câmbio real das exportações}

No que diz respeito às exportações, tanto de bens quanto de serviços, as estimativas para o modelo parametrizado geral indicam ser importante a quebra estrutural em outubro de 2002. Os 
gráficos para a soma acumulada dos resíduos e dos resíduos ao quadrado, CUSUM e CUSUMSQ, revelam importante instabilidade dos parâmetros entre 2002 e 2003 e corroboram a estimativa recursiva dos parâmetros. Além disto, não se rejeita a hipótese de normalidade dos resíduos em ambas representações. O teste assintótico de Breush-Godfrey para autocorrelação rejeita a hipótese de correlação serial nula dos resíduos. Os resultados foram sinais invertidos da elasticidade-câmbio em ambas as equações; ou seja, apresentam valores não esperados pela literatura econômica.

Diante disso, levaram-se a cabo investigações empíricas nos moldes anteriores para as exportações de bens e serviços para o período pós-eleições presidenciais, de novembro de 2002 até janeiro de 2006. A estrutura geral para ambas as equações superaram os testes gerais para especificação, estabilidade dos parâmetros, homocedasticidade e autocorrelação serial até a terceira ordem. ${ }^{12}$ Desta forma, passou-se à etapa de encontrar uma representação parcimoniosa da relação.

Com respeito à equação das exportações de bens, $x b_{t}$, a análise do geral para o específico resume-se em dois passos: no primeiro testou-se a significância conjunta do valor contemporâneo da primeira diferença do câmbio real até a quarta defasagem. Conforme relata a Tabela 6 , as estimativas nesse passo para significância conjunta para a coleção de defasagens recomendam a redução do modelo nessa direção.

\section{Tabela 6}

\begin{tabular}{ccccccc}
\hline Passo & Variável redundante & S.E da regressão & $\begin{array}{c}\text { Teste } F \\
\text { (valor-p) }\end{array}$ & $\begin{array}{c}\text { LR } \\
\text { (valor-p) }\end{array}$ & $\begin{array}{c}\mathrm{R}^{2} \\
\text { ajustado }\end{array}$ & SC \\
\hline 0 & & 0.0815 & & & 0.5493 & -1.2522 \\
1 & $\Delta q r_{t} a \Delta q r_{t-4}$ & 0.0765 & $0.3114(0.9012)$ & $\begin{array}{c}2.4516 \\
(0.7837)\end{array}$ & 0.6027 & -1.6590 \\
2 & $\Delta q r_{t-5}$ & 0.0806 & $4.3397(0.0461)$ & 5.4387 & 0.5585 & -1.6135 \\
\hline
\end{tabular}

Do segundo passo, emerge o modelo final para as exportações de bens, conforme equação abaixo:

$$
\begin{aligned}
& \Delta x b_{t}=6,8+0,043 t+0,69 q r_{t-1}-0,67 \Delta q r_{t-5}-1,67 x b_{t-1}+0,78 \Delta x b_{t-1}+0,59 \Delta x b_{t-2}+0,83 \Delta x b_{t-3}+0,47 \Delta x b_{t-4}+0,44 \Delta x b_{t-5} \\
& \begin{array}{lllllll}
(t) & (3,33)(5,41) & (2,85) & (-2,08) & (-5,66) & (3,39) & (3,23)
\end{array} \quad(4,74) \quad(2,66) \quad(3,12) \\
& R^{2}=0,70 ; F=7,40(\text { valor }-p=0,00)
\end{aligned}
$$

A especificação acima também foi submetida ao conjunto de testes de diagnósticos e obteve sucesso em geral. A estatística Jarque-Bera não rejeita o pressuposto de normalidade. A presença de autocorrelação serial nos resíduos é rejeitada pelo o teste de Breush-Godfrey. Os testes para resíduos ARCH não rejeitam a hipótese nula de resíduos homocedásticos. O teste de White rejeita a possibilidade de mudanças na variância dos resíduos. O teste para erros de especificação, teste RESET de Ramsey, não relata má especificação. A estatística LR para o teste de previsão de Chow, para os três últimos meses da amostra, não rejeita a hipótese de constância dos parâmetros. Os gráficos da

12 O teste de autocorrelação serial foi estimado para a segunda e terceira ordem, em virtude da perda de graus de liberdade. 
estimação recursiva dos coeficientes da equação e os resultados do par de testes para a invariabilidade dos parâmetros, baseados nas quantidades CUSUM e CUSUMSQ, confirmam a estabilidade dos parâmetros estimados.

Reescrevendo o modelo acima de forma a explicitar a equação de equilíbrio de longo prazo, chega-se a:

$\Delta x b_{t}=-1,67\left(x b_{t-1}-4,03-0,025 t-0,41 q r_{t-1}\right)-0,67 \Delta q r_{t-5}+0,78 \Delta x b_{t-1}+0,59 \Delta x b_{t-2}+0,83 \Delta x b_{t-3}+0,47 \Delta x b_{t-4}+0,44 \Delta x b_{t-5}$

Observa-se que as estimativas para o período em questão revelam que mudanças instantâneas no câmbio real não têm impacto sobre as exportações de bens. A relação de equilíbrio de longo prazo foi estimada com precisão e revela que a elasticidade-câmbio real de longo prazo das exportações de bens, $0,41 q r_{t-1}$, possui o sinal esperado. Destaca-se o alto valor estimado para o coeficiente de ajustamento do mecanismo de correção de erros, -1,67. Ele indica que desvios do equilíbrio serão corrigidos além do seu valor em mais $67 \%$. Da elasticidade de longo prazo das exportações de bens em relação ao câmbio real, deve ser retirado ainda o índice de Divísia, estimado para o período em 0,1956 .

Quanto às exportações de serviços, os resultados encontrados para a formulação ADL parametrizada geral indicam que a estrutura tem formulação correta. Os erros são homocedásticos e não apresentam correlação serial. Todavia, o teste para a normalidade dos resíduos - a estatística Jarque-Bera - rejeita a normalidade ao nível de significância de 3\%. Além disso, o teste de previsão de Chow para os três últimos meses da amostra rejeita a hipótese de constância dos parâmetros. Isso está relacionado ao pico acentuado no volume de exportações de serviços registrado em dezembro de 2005. Tanto as estimativas recursivas dos coeficientes quanto o gráfico da quantidade CUSUM relatam instabilidade dos parâmetros. Também para esse período, a estimativa para a elasticidade-câmbio real das exportações não apresenta o sinal esperado. Este resultado permanece caso se proceda à redução do modelo. Sendo assim, para esse período, também não se encontrou relação significante entre o câmbio real e as exportações de serviços.

\section{CONCLUSÕES}

Apesar de se verificar, no período estudado, perturbações significativas nos contextos políticos e econômicos, tanto no Brasil como no mercado internacional, que de certa forma parecem ter impactado as análises realizadas, pode-se concluir que as variações nas taxas de câmbio real exercem influência significativa sobre os componentes comerciais da conta corrente do balanço de pagamentos do Brasil. Os mecanismos de correção de erros sinalizaram que os desequilíbrios de curto prazo podem ser corrigidos num tempo pequeno.

Inicialmente, ao se analisarem os efeitos das variações cambiais em cada componente-macro da conta corrente (exportações de bens, exportação de serviços, importação de bens e importação de serviços), constatou-se, pelos testes aplicados, quebra estrutural significativa no modelo, no ano de 1999, por ocasião da mudança do regime cambial (de fixo para flutuante). 
Assim, adotou-se a alternativa de investigar a relação entre as variáveis de interesse e a variação do câmbio real em dois períodos distintos: entre janeiro de 1995 e junho de 1998, com regime de câmbio fixo, e de abril de 1999 a janeiro de 2006, com câmbio flutuante. Os resultados indicaram que, para o primeiro período, essa relação não foi significativa; o que pode ser considerado um resultado esperado, já que, num arranjo de estabilização econômica com âncora cambial, parece razoável que as contas de comércio exterior respondam mais a outros fatores, tais como os entraves institucionais, do que ao câmbio que permaneceu relativamente fixo.

Quanto ao segundo período, para as variáveis importação de bens e importação de serviços, após a realização dos testes e tratamento econométrico adequado, constatou-se a existência de uma sensibilidade significativa entre essas variáveis e as variações cambiais. No entanto, para as variáveis exportação de bens e exportação de serviços, os testes indicaram quebra estrutural em outubro de 2002 e, apesar da normalidade da maioria dos testes, os resultados apresentam sinais invertidos da elasticidade-câmbio em ambas as equações.

Diante disso, levaram-se a cabo investigações empíricas nos moldes anteriores para o período pós-eleições, de novembro de 2002 até janeiro de 2006. Os resultados indicam para a variável exportação de bens, após superados todos os testes econométricos previstos, a existência da mesma sensibilidade verificada nas variáveis anteriores em relação às alterações cambiais. Já em relação à variável exportação de serviços, além da ocorrência da instabilidade dos parâmetros, a estimativa não apresenta o sinal esperado. Sendo assim, não se encontrou relação significante entre o câmbio real e as exportações de serviços também para esse período.

Deve-se ressaltar a importância do índice de Divísia, que captou as mudanças institucionais tais como abertura comercial e desregulamentações, corrigindo os valores das elasticidades encontradas, com exceção apenas para a variável exportação de serviços, que, como visto, não teve o comportamento esperado.

De forma geral, esse trabalho reforça a existência de uma relação importante entre as variações da taxa de câmbio real efetiva e (os) as componentes de comércio exterior da conta corrente para a economia brasileira.

\section{REFERÊNCIAS}

ALMONACID, R. D.; SCRIMINI, G. A. Preços relativos e competitividade externa. Revista de Economia Política, v. 17, n. 266, p. 5-11, abr.-jun. 1997.

AMAZONAS, A.; BARROS, A. R. Manufactured exports from Brazil: determinants and consequences. Revista Brasileira de Economia, v. 50, n. 1, p. 73-100, jan.-mar. 1996.

BURSTEIN, A.; EICHENBAUM, M.; REBELO, S. Large devaluations and the real exchange rate. 2004. (NBER Working Paper 10986).

CARNEIRO, F. G.; MELLO Jr., L. R. Setor externo e a política cambial. Estudos Empresariais, ano 2, n. 2, maio-ago. 1997.

CARONE, G. Modeling de U. S. demand for imports through cointegration and error correction. Journal of Policy Modeling, v. 18, n. 1, p. 1-48, Feb. 996. 
CHEUNG, Y. W.; LAI, K. S. On the purchasing power parity puzzle. Journal of International Economics, n. 52, p. 321-330, 2000.

CHOUDHRY, N. N. Measuring the elasticity of the tax revenue: A Divisia index approach. Staff Papers, v. 22, p. 87-122, Mar. 1979.

DE GRAUWE, P.; GRIMALDI, M. The exchange rate and its fundamentals: a chaotic perspective. Munich: CES ifo, 2002. (Working Paper n. 6396).

DORNBUSCH, R. Expectations and exchange rate dynamics. Journal of Political Economy, Oct. 1976. . Open Economy Macroeconomics. N Y: Inc. Publishers, 1980.

EDWARDS, S. Real exchange rates, devaluation and adjustment: exchange rate policy in developing countries. Cambridge: MIT Press, 1989.

GONÇALVES, R.; CANUTO, O.; BAUMANN, R. A nova economia internacional: uma perspectiva brasileira. Rio de Janeiro: Editora Campus, 1998.

GRANGER, C. W. J. Some properties of time series data and their use in econometric model specification. Journal of Econometrics, 16, p. 121-130, 1981.

HENDRY, D. F.; Tremayne, A. R. Estimating systems of dynamic reduced form equations with vector autoregressive errors. International Economic Review, 17, p. 463-471, 1976.

HIMARIOS, D. Do devaluations improve the trade balance? The evidence revisited. Economic Inquiry, v. 27, n. 1, p. 143-168, Jan. 1989.

HULTEN, C. Divisia index numbers. Econométrica, v. 41, n.. 6, p. 1017-1025, Nov 1973.

MARÇAL, E.; MONTEIRO, W.; NISHIJIMA, M. Saldos comerciais e taxa de câmbio real: uma nova análise do caso brasileiro. In: XXXIII Encontro Nacional de Economia - ANPEC. 2005.

MESA, F.; ESTRADA, D. Tasa de cambio real y ajuste del sector externo. Planeacion e Desarrollo, v. XXVII, n. 1, enero-marzo 1996.

MUNDELL, R. A. Capital mobility and stabilization policy under fixed and flexible exchange rates. Canadian Journal of Economics and Political Science, 9, p. 475-485, 1963.

$\mathrm{Ng}$, S.; PERRON, P. Lag length selection and the construction of unit root tests with good size and power. Econometrica, v. 69, n. 6, p. 1519-1554, 2001.

OSKOOEE, M. B.; RHEE, H. J. Structural change in import demand behavior, the korean experience: a reexamination. Journal of Policy Modeling, v. 19, n. 2, p. 187-93, 1997.

OSTRY, J. D.; ROSE, A. K. An empirical evaluation of the macroeconomic effects of tariffs. Journal of International Money and Finance, v. 11, p. 63-79, Feb. 1992.

REINHART, Carmen M. Devaluation, relative prices, and international trade. Staff Papers, v. 42, n. 2, p. 290-312, June 1995.

REINHART, Carmen M.; ROGOFF, Kenneth S. The modern history of exchange rate arrangements: a reinterpretation. 2002. (NBER Working Paper 8963)

ROCHA, C. H. Wages, Exchange and competitiveness of Brazilian exports. Revista de Economia Política, v. 17, n. 266, p. 145-48, abr.-jun. 1997.

ROSE, A. K. Exchange rates and the trade balance: some evidence from developing countries. Economic Letters, v. 34, p. 271-75, Nov. 1990.

SACHSIDA, A.; TEIXEIRA, J. Impactos de desvalorizações cambiais sobre a conta corrente no Brasil. Revista Brasileira de Economia de Empresas, v. 1, n. 1, p. 63-71, set.-dez. 2001. 
STIGLITZ, J.; WEISS, A. A credit rationing in markets with imperfect information. American Economic

Review, 71, 1981.

\section{APÊNDICE}

A equação $y_{j ; t}=\alpha+\beta . t+\sum_{i=0}^{6} \pi_{i} q r_{t-i}+\sum_{i=1}^{6} \gamma_{i} y_{j ; t-i}+u_{t} \quad$ pode ser escrita em termos de polinômios no operador de defasagem até a sexta ordem:

$$
\Gamma(L) y_{t}=\alpha+\beta t+\Pi(L) q r_{t}+u_{t}
$$

Para tornar mais clara a exposição, omite-se o subscrito “ $j$ ” na notação. Assim, tem-se:

$$
\begin{aligned}
& \Pi(L)=\pi_{0}+\pi_{1} L+\pi_{2} L^{2}+\pi_{3} L^{3}+\pi_{4} L^{4}+\pi_{5} L^{5}+\pi_{6} L^{6} \\
& \Pi(L)=\Pi(1) L+(1-L)\left[\varphi_{0}+\varphi_{1} L+\varphi_{2} L^{2}+\varphi_{3} L^{3}+\varphi_{4} L^{4}+\varphi_{5} L^{5}\right]
\end{aligned}
$$

em que:

$\Pi(1)=\delta_{0}=\pi_{0}+\pi_{1}+\pi_{2}+\pi_{3}+\pi_{4}+\pi_{5}+\pi_{6} ;$

onde $\left\{\begin{array}{l}\pi_{0}=\varphi_{0} \\ \pi_{1}=\pi_{0}+\pi_{1}+\pi_{2}+\pi_{3}+\pi_{4}+\pi_{5}+\pi_{6}+\varphi_{1}-\varphi_{0} \\ \pi_{2}=\varphi_{2}-\varphi_{1} \\ \pi_{3}=\varphi_{3}-\varphi_{2} \\ \pi_{4}=\varphi_{4}-\varphi_{3} \\ \pi_{5}=\varphi_{5}-\varphi_{4} \\ \pi_{6}=-\varphi_{5}\end{array} \Rightarrow\left\{\begin{array}{l}\varphi_{0}=\pi_{0} \\ \varphi_{1}=-\left(\pi_{2}+\pi_{3}+\pi_{4}+\pi_{5}+\pi_{6}\right) \\ \varphi_{2}=-\left(\pi_{3}+\pi_{4}+\pi_{5}+\pi_{6}\right) \\ \varphi_{3}=-\left(\pi_{4}+\pi_{5}+\pi_{6}\right) \\ \varphi_{4}=-\left(\pi_{5}+\pi_{6}\right) \\ \varphi_{5}=-\pi_{6}\end{array}\right.\right.$

A soma dos parâmetros $\pi_{i}$ é o coeficiente de L na $2^{\text {a }}$ linha acima, e os $\varphi_{i}$ são os coeficientes dos $\Delta q r_{t}$ até $\Delta q r_{t-5}$. Multiplicando a $2^{\mathrm{a}}$ linha da expressão acima por $q r_{t}$ e expandindo, tem-se:

$$
\begin{aligned}
& \Pi(L) q r_{t}=\Pi(1) L q r_{t}+(1-L)\left[\varphi_{0}+\varphi_{1} L+\varphi_{2} L^{2}+\varphi_{3} L^{3}+\varphi_{4} L^{4}+\varphi_{5} L^{5}\right] q r_{t} \\
& \Pi(L) q r_{t}=\delta_{0} q r_{t-1}+\sum_{i=0}^{5} \varphi_{i} \Delta q r_{t-i}
\end{aligned}
$$

Uma transformação semelhante pode ser usada na variável dependente: 


$$
\begin{aligned}
& \Gamma(L) y_{t}=\Delta y_{t}+\left[\Gamma(1) y_{t-1}+\theta_{1} \Delta y_{t-1}+\theta_{2} \Delta y_{t-2}+\theta_{3} \Delta y_{t-3}+\theta_{4} \Delta y_{t-4}+\theta_{5} \Delta y_{t-5}\right] \\
& \text { em que: } \\
& \Gamma(L)=1-\gamma_{1} L-\gamma_{2} L^{2}-\gamma_{3} L^{3}-\gamma_{4} L^{4}-\gamma_{5} L^{5}-\gamma_{6} L^{6} \\
& \Gamma(L)=\Gamma(1) L+(1-L)\left[1+\theta_{1} L+\theta_{2} L^{2}+\theta_{3} L^{3}+\theta_{4} L^{4}+\theta_{5} L^{5}\right] \\
& \Gamma(1)=\theta_{0}=1-\gamma_{1}-\gamma_{2}-\gamma_{3}-\gamma_{4}-\gamma_{5}-\gamma_{6}
\end{aligned}
$$

o que permite escrever:

$$
\Delta y_{t}=\alpha+\beta t+\delta_{0} q r_{t-1}+\sum_{i=0}^{5} \varphi_{i} \Delta q r_{t-i}+\theta_{0} y_{j ; t-1}+\sum_{i=1}^{5} \theta_{i} \Delta y_{t-i}+u_{t}
$$

como antes, $y_{j ; t}$ representa as variáveis de interesse: $x s ; x b ; m s ; m b$; e qro logaritmo do câmbio real. 